\title{
STRATEGY AND PHILOSOPHY OF DISTRICT HEATING SYSTEMS CONTROL
}

\author{
Jaroslav BALÁTÉ, Bronislav CHRAMCOV, Michal PRINC \\ Instinute of Information Technologies. \\ Faculty of Technologv. Tomas Buta Unversiny in Zin. \\ Mosmi 5130. 76001 Zlin, Cacih Republic.

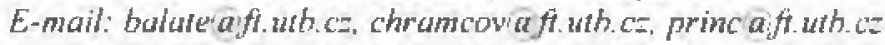

\begin{abstract}
The District Heating Systems (DHS) are being developed in large cities in accordance with their growth. The DHS are formed by enlarging networks of heat distribution to consumers and at the same time they interconnect the heat sources gradually built. DHS is used in larger cities of some European countries e.g. in Germany, France, Denmark, Finland, Sweden, Netherlands, Czech Republic, Poland and others. Production teclnology of heat by meass of combined production of power and heat (CHP) is an important way to increasing of thermal efficiency of closed thermal loop. The paper shows the system access to the control of extensive DHS - controlled plant. It concerns automatic control of technological string "production, transport + distribution, consumption" of extensive district heating and that is the contribution of this paper. Control by means of advanced control algorithms is a tool (up to now neglect) for decreasing cost of energy and increasing the level of environment protection. Coptright re 2003 IFAC
\end{abstract}

Keywords: District Heating. Control Algorithms, Control System. Hierarchical Control, Combined Heat and Power - CHP, Hydrothermal Power Systems.

\section{INTRODUCTION}

Cogeneration of Power and Heat is an important way to increasing of thermal efficiency of closed thermal loop. The experiences in design of Control Strategy for Extensive District Heating Svstem in the towns Bmo and Prague in Czech Republic are summarised in the paper. It involves the connection of main author's operational experiences gained during many years of his work in the Power and Heating Plant and $h$ is further scientific - research activities on the technical university in co-operation with his colleagues, PhD students and with his students. The design of control strategy shows the basic concept of control methods of the districi heating system of a specific locations in town Bmo and in town Prague. Each district heating system has its specific leatures and therefore it is necessary to create a philosophy of control for each of them. From the point of view of control, this philosophy consists of both general regularities and special features of a specific locality. The idea of a system approach to design of technological string control "production. transport + distribution. consumption" resulted from the specific solution of the way of control in real time and also from short-lime preparation of districl heating operation in region of $\mathrm{Bmo}$. Czech Republic during the last decade of 20 th century. The knowledge of operation and experience motivated the author to creating the methods and conception of control of this technological string.

At present it is known from the literature that the problems of optimum control of combined heat and power production (CHP) in sources and also systems of automatic heat consumption control are solved only separately. Very few attention is paid to analysis of static and dynamic behaviour of heat networks and utilization of these features for operation control of these networks. There are no any works dealing with elimination of transport delay in transport of heat in 
heat networks. Publications dealing with system approach to control of the technological string as a controlled plant are missing at all. This fact was the motivated cause for solving a new problem.

\section{CHARACTERISATION OF CONTROL OF DISTRICT HEATING SYSTEMIDHSCI}

The function of DHS is to ensure permanently all economically justifjed and socially necessary demands for supply of energy to all consumers namely at minimum costs and when respecting further important aspects e. g. of environment. The demands of consumers on the delivered energy can be specified by the following requirements:

- to provide dalivery of justified quantity of energy to all consumers according to their needs varying in time.

- to provide stable and unintemapted delivery of energy,

- to provide permanent delivery of energy within the limits of specilied quality indexes (e.gtemperature of hot water in hot-water piping. steam pressurc and temperature in steam piping or possibly frequency and voltage of electric energy at combined production of electric energy and heat etc.

It is necessary to harmonise the demands of consumers on energy with the requirement of maximum operating economy of the whole DHS i.e. both in the production and delivery of heat witt emphasis on complying with ecological indexes in the respective locality.

Economical control of the subsystem of heat energy production consists of two tasks i.e. of ecomomical distribution of load between sepurate co-rperating sources in circle heal netwrork including economical loud distribution between separate production anis. inside the sources and further also of determination of the suiloble composition of co-operating sources including determination of suitable composition of co-operating units inside the source as well as in determination of sulable ecomomicaly based saring and switching off the produclion wits or possibly also the whole sources.

The important fact is the production technoloys using combined production of power and heat.

Economical oneration of the heat distribution network subsysten, heat exchanger stations and consumer's equipment require heat output control in three levels of hierarchy:

- control in the source of heat con the inpul into the heat network: or possibly the forced limitation of heat supply):

- control in the transfer station:

- control in the system of consumers.

Economical control in the system of consumers is fully in competence of consumers. Control of heat exchanger stations operation is from the point of view of attomatic control quite autonomous: however here it is necessary to think over also further possibilities namely at large consumers.
For heat supply control in DHS the heat supply control in the source of heat is decisive i. e. On the input into the beat network.

The system of district heating - for centralised heat supply is by its character large extensive system. There exists a great number of dependent variables (e.g. relative increases of outputs of separate production units of sources); it is necessary to fix their value always for a certain value of one or more (of vector) independent variables (e.g. change in demand for energy supply to consumers. influence of change in combined production of heat and electric energy, influence of weather conditions, changes of parameters of fuel supplied to the sources etc.).

In this paper there is considered the circular steant heat network supplied by several heat sources. In these sources there are heat exchangers steam-hot water for supplying heat to consumers in autonomous (local) radial networks.

\section{BRIEF CHARACTERISTIC OF SPECIFIC LOCALITIES OF DHS}

\section{DHS in Brno}

According to the analysis the supposed locality has approx. 400 thousand permanently resident people namely in approx. 164 thousand flats. The total heat input has been $3500 \mathrm{MW}_{\mathrm{t}}$. This total heat consumplion is supplied approx. $30 \%$ from Heat Supply System. It is a circle steam network with local radial hot-water networks in each cooperating heat source. Delivery of heat by means of hot-water piping from the nuclear power plant situated in a distance of $42 \mathrm{~km}$ was considered (Baláté. 1988).

The following terms are used in further text:

- Distrit Heuting Strtem (DHS), system with cooperaling Power and Healing Plant and Heating Plants - 10 be understood as present heat sources and heat networks in the supposed locality.

- Integrated Disfrict Healing Sis/em (IDHS) - to be understood as co-operation of DHS with the heal source in ruclear power plant situated in distance about $40 \mathrm{~km}$; according to the design it had to supply heat using the heal feeder to the blocks of Hats in housing estates of the town or possibly to the other connected consumers.

Principal scheme of the design to build up an Integrated District Heating System is on Fig. I. The design including the perspective heat network development in supposed locality and by using the heat source in nuclear power plant is shown on Fig. 2 .

The used abbreviations have the following meaning: TBS - Power and Healing Plant. S - TBS - Peak Boilers in TBS, further VSB. VCM. VBS - Heating Plants, ZT KPS. ZT IBS. ZT Zetor - Power and Heating Plants in industrial factories, TKO Incinerating Plant of Solid Municipal Waste. JE Nuclear Power Plane. 


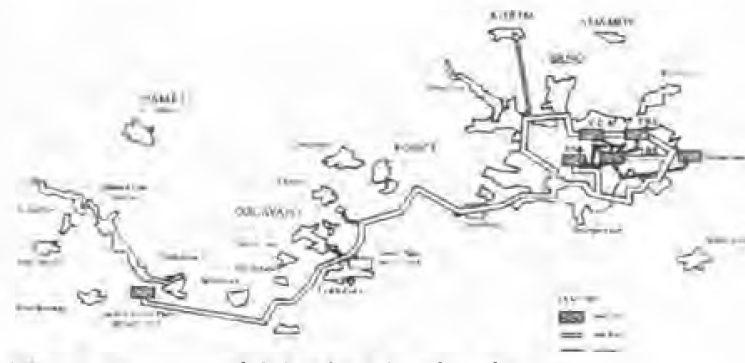

Fig. 1. Integrated Districl Hcating System.

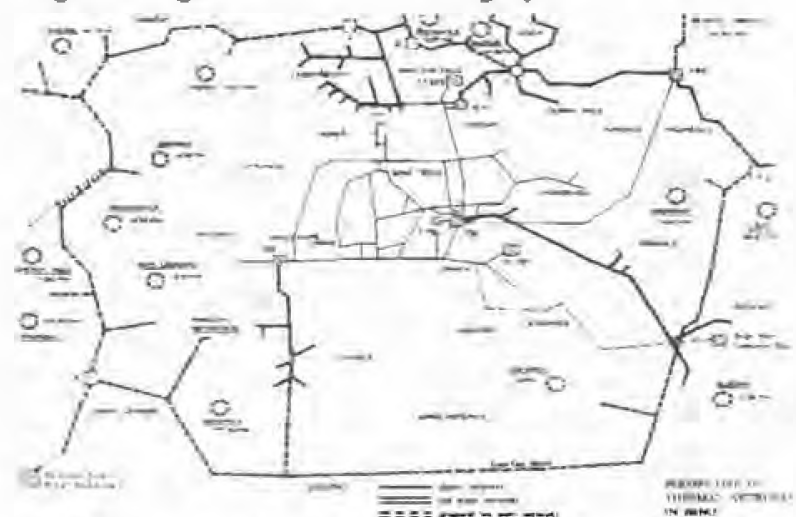

Fig. 2. Perspective of thermal networks in supposed locality.

It is obvious to see from these figures that IDHS foms the original (present) sources which are interconnected by circle steam network and the heat feeder from the nuclear power plant in which had to supply heat in hot water as heat - transfer medium to blacks of fhats in new housing estates on the outskins of town. These housing estates are at present equipped by gas boiler rooms but these should have been reconstructed to exchange stations connected to north-west and south-east branches of hot water bypass piping of the supposed town. The heat sources TBS, VSB, VBS and also VCM have their own heat exchangers which deliver heat to their own autonomous hot-water systems. The aim was to intercomnect these autonomous hot-water systems with branches of hol-water by-pass piping. Thus the extensive hut-water network had to come into being which would be equipped by sector closures for the possibility to realise changes in network configuration in dependence to the heat consumption in blocks of flals.

\subsection{DHS in Pragu'}

It is i hot-water network with installed beat output of $1995 \mathrm{MW}$ and electrical output of $138 \mathrm{MW}_{\mathrm{E}}$. The $\mathrm{CPH}$ source cooptrating from the distance of $36 \mathrm{~km}$ is connected to the origina! DHS. It is an analugical problem as above-mentioned wa) of control (Balate. 1996).

\section{PHILOSOPHY OF CONTROL METHOD}

Philosophy of control is according to author's opinion a basic view of control (i.e. perhaps also by a manual method on a base of operators "s experience) and this method (way) of control has to be made objective by means of utilization of objective methods of control supported by control metliods using the method of automatic and automated control or using the method of advarced control algorithms.

From the discussion with the operating organisation in locality of DHS in Brno ensued that the control will be realised as follows:

1. Short-lime and long-time preparation in dependence to the development trend of weather. cooperation with the superior energy dispatching and with the heat supply dispatching of operating organisation.

2. Operational control in real time in dependence to immediate heat consumption.

The aim of the control has been fixed:

To utilise the source of heat in nuclear power plant as much as possible: to supply the rest of necessary heat from the existing sources of DHS with the requirement of minimum heal consumption in fuel and fullilling ecological indexes.

For fulfilling the aims of control the control system should ensure activities illustrated by the algorithms of control in the scheme on the Fig. 3. The separate blocks represent activities which concem both the preparation of heat production i.e. covering the predicted course of daily heat supply diagram and control of technological string in real time.

The Incinerating Plant TKO has a specific standing. The task of the incinerating plant is the liquidation of solid municipal waste and therefore the heat production is a secondary product. It will be a duty of IDHS dispatcher to withdraw the heat produced in the incinerating plant and to include it to the bottom part of HSDD in steam i. e. to the area of basic load. The supplied outputs produced in Power and Heating Plants of Factories will be located in the same way Lone-time and short-time preparation includes the activities specified in paragraphs No, I. 2, 3 and 4 . Operational control in real time includes the activities according to paragraphs No. 5.6.7.8.9 and 10 . The sequence and reassuming the separate activities is obvious from the Figr 3 .

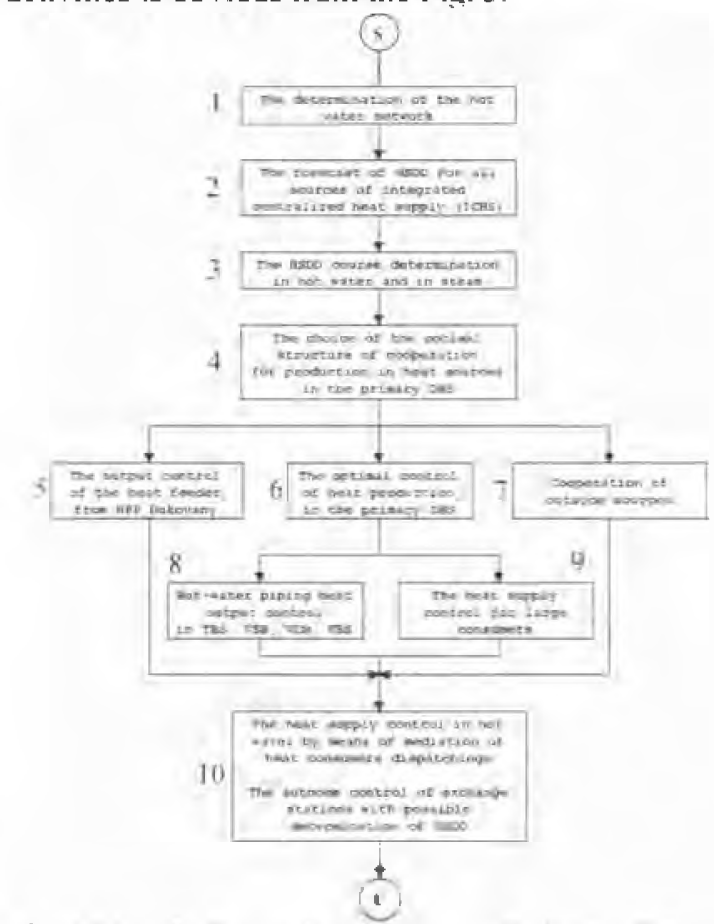

Fig. 3. Principal algorilhm of control philosophy of district heating of Brno. 


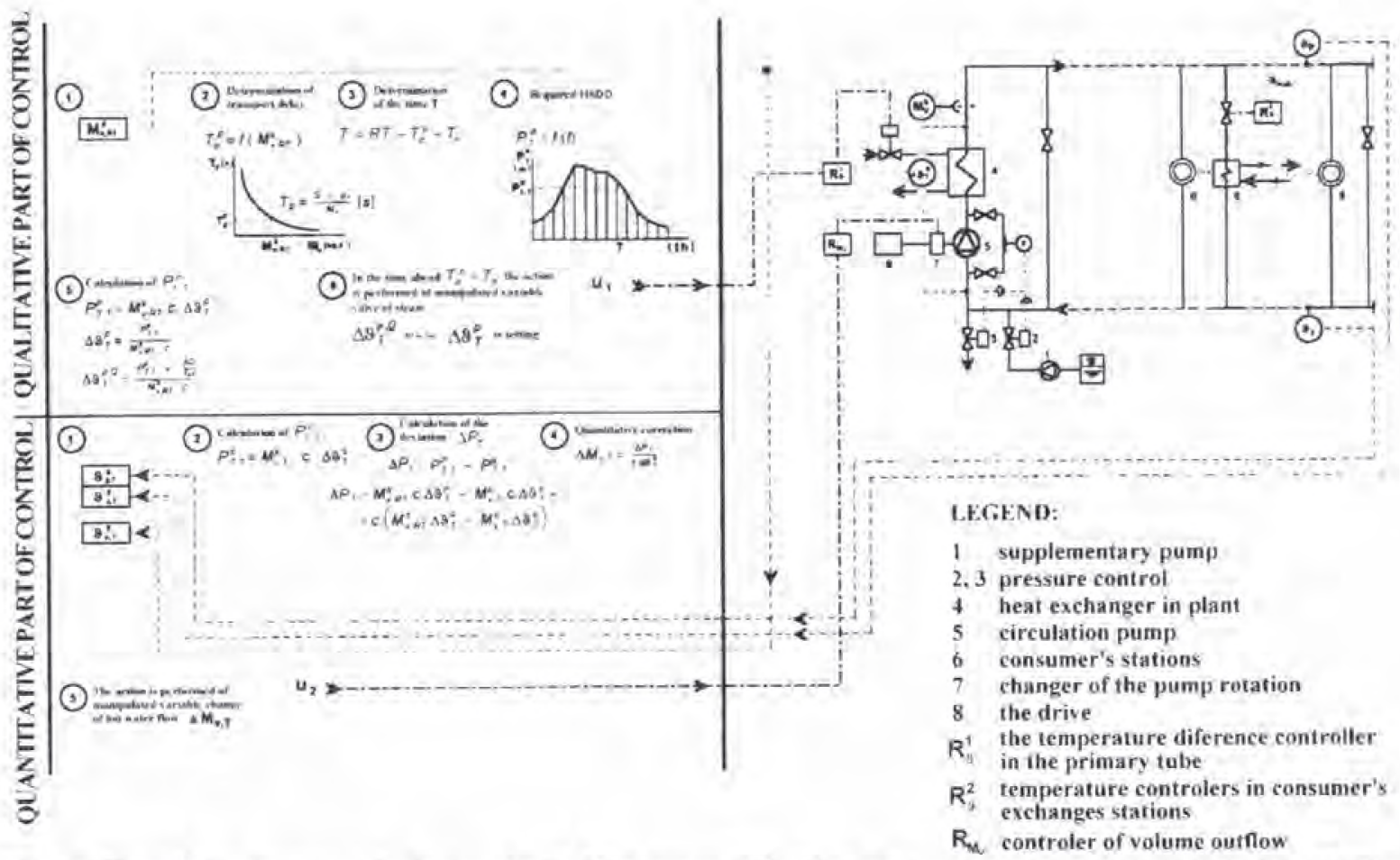

Fig. 4. The qualitative-quantitative method of hot-water piping heat output control (Balátẻ and Sysala, 1998).

\section{SUMMARY OF THE METHODS USED FOR SOLUTION OF AUTOMATED CONTROL OF IDHS}

The following methods has been or are soived in our laboratory:

\section{For heat oroduction:}

1.1. Optimisation of heat production in production plant by the method of linear or non-linear programming.

1 2. Making up criterion of regime optimum for $\mathrm{co}-$ operation of power and heating plants and heating plants by heat supplying in district heating system namely from the point of view of costs decreasing of produced heat and power and of increasing the environment protection.

I.3. Making up algorithm for selecting optimum operational composition of sources of DHS including elaborating methods of calculating costs of a change of DHS operational composition or operational variant in separate sources.

1.4. Analysis of static and dynamic fealures of main technoloyic equipment of DHS sources.

\section{For heat distribution:}

3.I. Analys of static features of heat networks and their utilisation for heat distribution control namely-stean networks. - hot-water networks.

2.2. Making up algorithm for qualitativequantitative method of control of heat delivery by hot-water piping using continuously calculated prediction of heat supply daily diagram. The function of the algorithm is obvious from the Fig. 4. 2.3. Automation of operation of consumer's heat exchangers including visualisation of technologic process.

\section{For control of the whale DHS:}

3.1. Co-ordination of sub-system control of the DHS i. e. of production plants and distribution of heat.
3.2. Utilisation of prediction calculation of course of daily diagram of heat supply for control of DHS. 3.3. Design of function of Heat Supply Dispatching including its co-operation with Heat Supply Dispatchings of operalion organisations or possibly with direct large consumers.

3.4. Design of instrumentation of Heat Supply Dispatching by discrete distributed control system covering corresponding hierarchy of controt.

The following part of this paper brings near the analysis of the static features of heat networks and their use for heal distribution control and of the prediction calculation of the course of heat supply daily diagram.

\section{STATIC ANALYSIS OF HEAT NETWORKS OPERATION}

As a tool for the analysis of behaviour of the heat networks. a calculation program for simulation of pressure. through-flow and temperature relations in distributing stean and hot water networks was created. For the calculation of the mass flow in the separate branches of a circular piping system a method called 'crircle flow was used. It is an analogy with the method of loop current. which is very often used in electrical engireering. The mass flow corresponds here to the electric current. the pressure is proportional to the voltage and the hydraulic resistance corresponds to the electric resistance. apply the Isr and Ind Kirchhoff s Law to the del ir's network. we obtain a system of non-linear algebraic equations. The proccdure is shown on a simple network having four points of junction and $\operatorname{six}$ branches (see Fig. 5) 


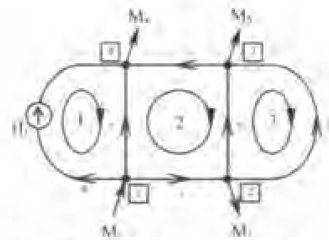

Fig. 5. Scheme of sample network.

We mark the unknown mass flow of the liquid in the $i-t h$ branch by symbol $x_{1}$. the taken away/delivered quantity in the $\mathrm{i}$-th point of junction by symbol $\mathrm{M}_{1}$ and the active pressure in the $i$-th branch by $H_{1}$. From 1st Kirchhoff's Law it results: The sum of all flow quantities for a determined point of junction equals zero. Therefore. we can write the following equations of balance:

Point of junction I

$$
\begin{aligned}
& -x_{1}-x_{1}-x_{4}+M_{1}=0 . \\
& x_{1}-x_{2}-x_{17}-M_{4}=0 . \\
& x_{2}-x_{3}+x_{0}-M_{3}=0 .
\end{aligned}
$$

Point of junction 3

The pressure losses in branches $\Delta p$ arising at flowing of the liquid through the circular piping can be calculated according to the following formula

$$
\Delta p=\left(\frac{8 L}{\pi^{2} d^{2} p\left(2 \log \left(3.72 \frac{d}{k}\right)\right)^{2}}+\frac{8 \sum \xi}{\pi^{2} d^{4} \rho} x^{2}=r x^{2}\right.
$$

where: $L[m]$ - length of straight sectors of the piping, $d[m]$ - inside diameter of the piping. $p$ [kg. $\left.\mathrm{m}^{-3}\right]$ - specific mass of the flowing liquid. $\mathrm{k}[\mathrm{m}]$ absolute roughness of the inside surface of the piping, $\Sigma \xi[-]$ - sum of the coefficients of the inside resistance of the piping. $\times\left[\mathrm{kg} \cdot \mathrm{s}^{-1}\right]$ - mass flow through the piping. $r\left[P a \cdot s^{7} \cdot \mathrm{kg}^{-\gamma}\right]$ - hydraulic resistance of the piping.

For the chosen loops I. 2 and 3 (see Fig. 5) we can write according to the formula (2) and according to the 2nd Kirchioft's Law the following equations for the pressure losses in branches:

$$
\begin{aligned}
& \text { Loop } 1 \quad r_{4}\left|x_{4}\right| x_{4}-r_{5}\left|x_{3}\right| x_{5}-H_{1}=0 \text {. }
\end{aligned}
$$

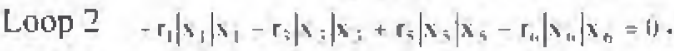

$$
\begin{aligned}
& -T_{2}\left|x_{2}\right| x_{2}+r_{h}\left|x_{h}\right| x_{h b}=01
\end{aligned}
$$

To solve the system of non-linear equations represented in our case by equation (1) and (3) we shall use the Newton's iterative method.

The calculation runs on the basis of determined network parameters. source delivery and the consumer's demands. The results of calculation can be shown on the screen in the form of tables or simple column graphs. see Fig.7. Presented data are results of the calculation. which was worked out for the heat network described in the Fig.6.

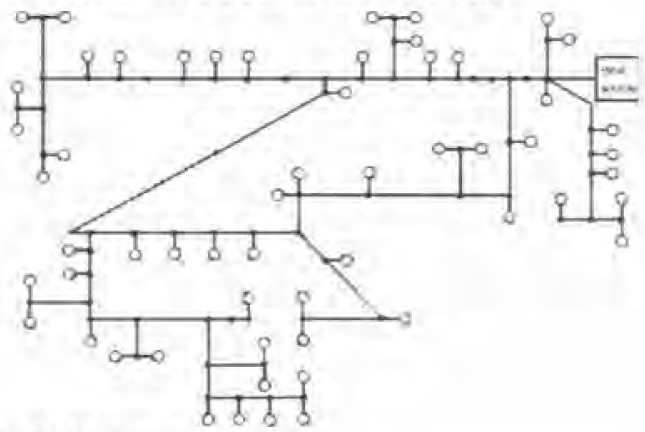

Fig.6. Network topoloy

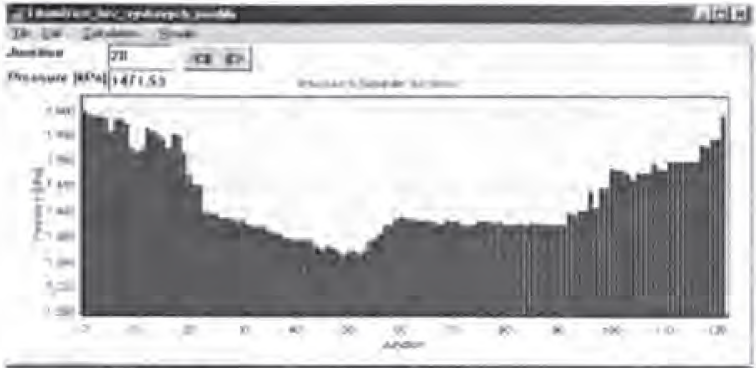

Fig. 7. Results presentation in graphs.

The practical importance of the program is not only for design of distributing networks, but above all in operation of district heating systems. The possibility of simulation of relations in the network for various operating conditions, j.e. for instantaneous output of sources or for instantaneous consumplions is very useful for dispatchers in power and heating plants. This can be a contribution not only from technica! aspects but also from economic ones.

\section{PREDICTION OF COURSE OF HEAT SUPPLY DAILY DIAGRAM}

An improvement of technological process control level can be achieved by time series analysis in order to predict their future behaviour. We can find art application of this prediction also by the control in the Centralised Heat Supply System (CHSS), especially for control of hot-water piping heat output. The forecast is determined for two ways of using: 1. The predictions of whole heat supply daily diagram (HSDD). Forecast of HSDD (see Fig.8) of whole CHSS is utilised for the purpose of heat production control and thus for the purpose of the optimal distribution loading between cooperative production sources and production units inside this sources.

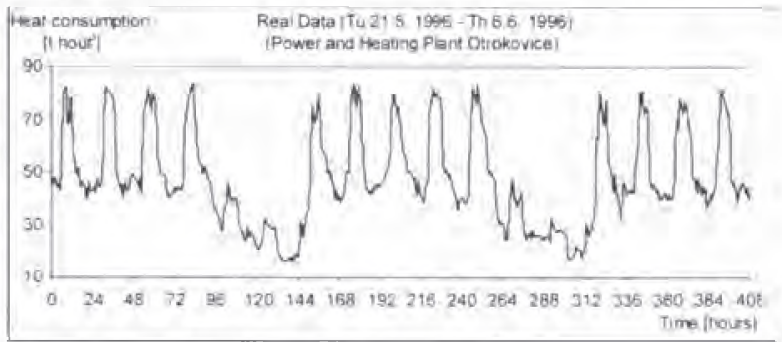

Fig. 8. Heat Supply Daily Diagram.

2. The prediction is detenmined for continuous acquisition of necessary heat output ahead of the lime. It depends on Iransport delay, namely in the range of 2 up to 16 hours depending on distance of heat sources from consumers. and it is different for each tocality.

The methods of foresast Most of methods which solve the prediction of HSDD are based on mass data processing. But this method has a big disadvantage. It consists of real data out of date. From this point of view it is available to use the forecast methods according to the methodology of Box-Jenkins (1976). This method works with fixed number of values. which are updated for each sampling period. The Bor-alonkin. (BS/) merhod. This methodology is based on the correlation analysis of time series and it works with stochastic models. which enable to give a 
true picture of trend component and also of periodic components. The course of time series of HSDD contains two periodic components (daily and weekly period). But general model according to BJ enables to describe only one periodic component. We can propose two possible approaches to calculation of forecast to describe both periodic components.

- The method that uses the model with double filtration

- The method - superposition of models

First we introduce simplified form (5) of general model according to $\mathrm{B}$ J for the next using when there is used substitution in the form (4). We can find more detailed analysis of general model in work.

$$
\begin{gathered}
\mathrm{F}=\Phi_{\mathrm{p}}^{-1}\left(\mathrm{~B}^{\mathrm{s}}\right) \cdot \varphi_{p}^{-1}(\mathrm{~B}) \cdot \Theta_{0}\left(\mathrm{~B}^{\mathrm{s}}\right) \cdot \theta_{\mathrm{q}}(\mathrm{B}) \cdot \nabla_{s}^{\mathrm{D}} \cdot \nabla^{\mathrm{d}} \\
\mathrm{z}_{\mathrm{i}}=\mathrm{F} \cdot \mathrm{a}_{\mathrm{i}}
\end{gathered}
$$

The mathod that ases model wh donte filtation We can describe model with double filtration through the substitution (4). The model in the form (6) is the result of it.

$$
z_{1}=F \cdot \nabla_{s^{+}}^{D^{+}+a_{1}}
$$

where: D - degree of seasonal difference - daily (in equation 4), $D^{*}$ - demree of seasonal difference weekly. 5 - daily period (in equation 4). $s^{*}$ - weekly period

It is important to adhere to the general plan for using the method that uses model with double tiltration for calculation of HSDD prediction

The model in the form (6) enables to describe the HSDD course (i.e. it describes daily periodic component and also weekly one). It can be used for analysis and prediction of following regular influence of calendar (Saturday, Sunday).

The mathod - superposition of models. We can use second method i.e. stuperposition of models for elimination of regular influence of calendar. This method is being used on two models in the form (5) These models are discemed by means of symbols * and **. The time series matked by symbol * is series of values of HSDD outputs in every hour the sampling period is I hour). The time series marked by means of symbol ** is series of values of heat consumption per day (the sampling period is 1 day). The plan of calculating prediction by means of the method of superposition of models is shown on the Fig․ 9.

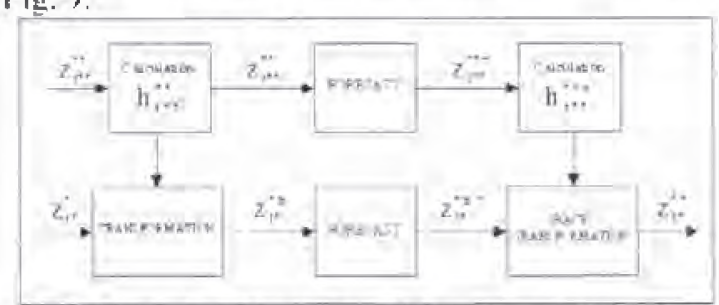

Fig. 9. Superposition of models - plan of calculating prediction

Results of Calculation of HSDD Pursuant to the mentioned theory and literature a program was created in Matlab. This program enables to choose available mathematical siatistical model for calculation of prediction of HSDD course and it is used for forecast of HSDD, which is an essential part of control of DHS by means of qualtative- quantitative method. All testing and calculations are based on lot of real data. These data were obtained in specific locality. Examples of results of the forecast calculations are shown on the next figure.

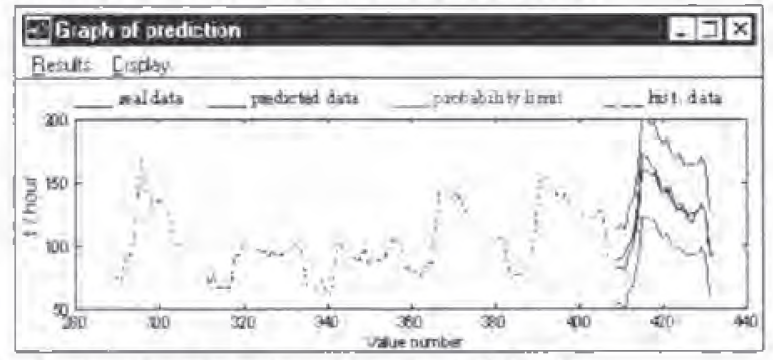

Fig. 10. Results of prediction of HSDD.

\section{CONCLUSION}

The complicated process of technological string of heal production, Iransfer and distribution of heat or possibly of heat consumption, as it was mentioned above, requires the system approach when solving the concept of autontated control by means of advanced control algorithms. We believe that the intelleclual process when deternining the philosophy of control can be interesting and useful for the technical public. It is a demonstration of necessity to know technology for designers of control system.

It is necessary to stress that each DHS has its specific fealures which have to be solved specifically and individually.

We can inform readers that this idea of the presented paper was the base of the proposal in the frame of 5 th Framework Programme of EC called: Cost Effective and Environmental Compatible Operation of District Heating Susems by means of Advanced Control Algorilhms

\section{REFERENCES}

Selected research works in the field of District Heating Control:

Balatê. J. at al. (1988). The study of district heoting control in Brnw. Research work No: VZ-HSZ070 in Czech. TU Bmo. Faculty of Mechanical Engineering. Brno.

Balate. J. (1996). District heating in Prague Design of Philosmbl of Control. Research Work No: KART-PTAS 1996 in Czech. TU Bno. Faculty of Technoloys in Zlin. Zlin.

Special appreciation with the gold medal of the patent No: 279253 - CZ:

Baláté. J. (1997). Compold de la produchion themilue dans circuits de chaldar at methode wilise. 46th World Exhibition of Innovation. Research and New Technology. Brussels EUREKA 97. Brusscl. Belyium.

Balàte. J. and T. Sysala (1998). The Way of District Heating Output Control by Means of Hot Water Piping. In: Preprints: 5th IFAC Workshop on Algowishms and Arohisectures for Real-Time Commol-A.ARTC YSC'an'zn. Mexico.

Box. G.E.P. and G.M. Jenkins (1976). Time Series inulisis, Forecasting and $C^{t}$ morol. Holden Day. San Francisco. 